\title{
Fast Finite Element Analysis of Weld Residual Stress in Large-Diameter Thick-Walled Stainless Steel Pipe Joints and Its Experimental Validation*
}

\author{
by Akira Maekawa**, Hisashi Serizawa***, Keiji Nakacho*** and Hidekazu Murakawa***
}

\begin{abstract}
Weld residual stress analysis is an effective method for integrity evaluation of welding structures. However, faster computation techniques have been demanded because of the huge calculation time needed for the analysis. Recently, accurate weld residual stress evaluation based on faster three-dimensional analysis has become available through development of the iterative substructure method. In this study, computing performance of the three-dimensional weld residual stress analysis using the iterative substructure method was examined for a large-diameter thick-walled stainless steel pipe joint and then the analysis accuracy was validated by the weld residual stress distribution measured using the inherent strain method. These results demonstrated that the analysis technique using the iterative substructure method could accurately calculate large-scale welding problems within practical times.
\end{abstract}

Key Words: Weld residual stress, Finite element analysis, Iterative substructure method, Inherent strain method, Fast computation, Validation

\section{Introduction}

There are many weld zones for the apparatuses and pipes in power plants and industrial process plants. Residual stress generated in these zones by the welding process is the most important factor influencing maintenance of structural integrity. Presently, weld residual stress is evaluated by measurements of actual structures and mock-ups, approximate calculations using simple evaluation formulas, and numerical simulations using thermal elastic plastic analysis. Among them, weld residual stress evaluation using numerical simulations has become more popular owing to innovation of new computing technologies and simulation techniques.

Weld residual stress analysis is an effective method to evaluate the stress distribution resident in weld structures. However, a huge computation time is required for the finite element analysis because weld phenomena are transient problems with strong nonlinearity, and faster computation techniques have been demanded. Recently, faster weld residual stress analysis using a precise three-dimensional (3D) model has become available through development of the iterative substructure method (ISM) ${ }^{1)}$. The analysis accuracy and computing performance, however, have not been sufficiently validated yet for the weld residual stress analysis technique based on ISM. Only a few validation cases $^{2)}$ have been reported and more should be done.

In this study, the computation speed performance of the $3 \mathrm{D}$ weld residual stress analysis using the ISM was examined for a large-diameter thick-walled stainless steel pipe joint and then the

\footnotetext{
${ }^{*}$ Received: 2012.11 .28

Institute of Nuclear Safety System, Inc.

${ }^{* * *}$ Member, Joining and Welding Research Institute, Osaka University
}

analysis accuracy was validated by the weld residual stress distribution measured using the inherent strain method ${ }^{3)}$ which is known to be an accurate measurement technique due to its use of inversion analysis and statistical estimation.

\section{Iterative substructure method (ISM) ${ }^{1)}$}

The numerical analysis of multi-pass weld structures such as pipe joints takes more than a few weeks to run, even though the most popular general purpose finite element analysis codes are used. More efficient analysis methods are needed to predict weld residual stress and weld distortion of actual plant components and ISM is one of the candidate methods.

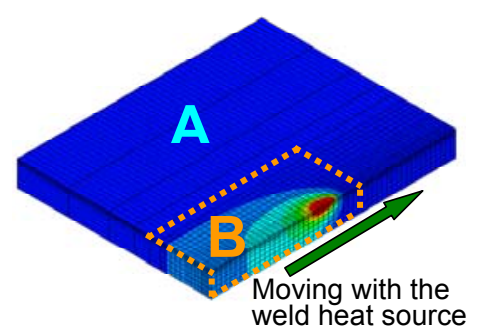

Fig. 1 Concept of the iterative substructure method (ISM): A, linear behavior region; $\mathrm{B}$, nonlinear behavior region

Welding problems have two distinctive features: they have nonlinear mechanical behavior in a tiny region around the weld heat source which is the weld torch and linear behavior in most other regions; and the nonlinear region moves with the weld heat source.

General welding simulation methods solve an entire weld problem as a large scale nonlinear problem with time iteratively even though only a small part of the problem has nonlinear behavior. This approach demands a huge calculation time. When 
the problem is separated into linear and nonlinear regions and they are calculated independently while maintaining continuity through the iterations, the solution time can be shortened. A technique to enhance calculation efficiency based on this idea is the ISM as shown in Fig.1.

\section{Weld residual stress analysis}

\subsection{Mock-up of a welded pipe joint}

Two $250 \mathrm{~mm}$ long straight pipes with the standard size of $300 \mathrm{~A}$ Sch160 (Outer diameter: $318.5 \mathrm{~mm}$ and wall thickness: $33.3 \mathrm{~mm}$ ) were butt-welded to get a mock-up welded pipe joint. The pipe and the weld were type 316L stainless steel (Pipe, SUS316LTP (JIS G 3459) and weld, Y316L (JIS Z 3321)). After making a U-shaped groove at one edge of the pipes, butt-welding was done at all positions using gas tungsten arch welding (TIG welding) with welding current of 63 to $180 \mathrm{~A}$, welding voltage of $20 \mathrm{~V}$, and welding speed around $100 \mathrm{~mm} / \mathrm{min}$. Circumferential welding in the direction from $0^{\circ}$ to $180^{\circ}$ was done on both sides at $90^{\circ}$ and $270^{\circ}$ on the free-free boundary condition. The $0^{\circ}$ direction of the pipes was located at the bottom. When the mock-up was completed, it was a multi-pass welding joint with 18 layers and 39 passes. The multi-pass welding was composed of 1 pass for the 1st and 2nd layers, 2 passes for the 3rd to 13th layers and 3 passes for the 14th to 18th layers. Photos of the mock-up and the macro structure of the weld cross section are shown in Figs. 2 and 3 , respectively.

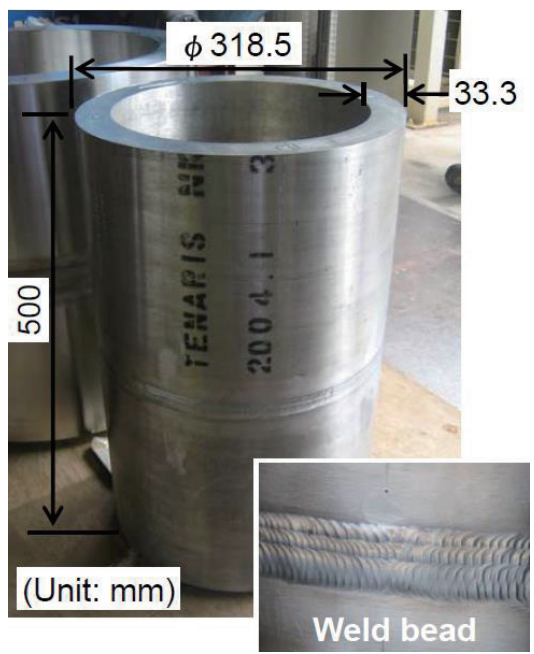

Fig. 2 Mock-up of welded pipe joint

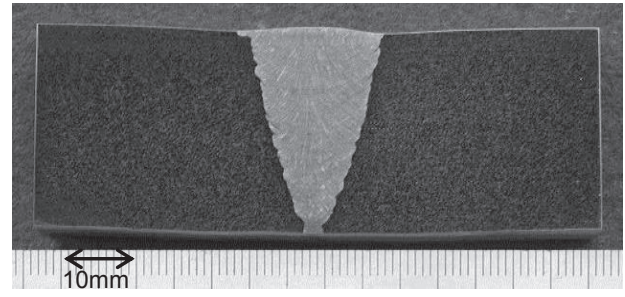

Fig. 3 Weld cross section of mock-up

\subsection{Finite element analysis model}

Figure 4 shows the analysis model made on the basis of the geometry and dimensions in Figs.2 and 3. The numbers of nodes and elements were 52,900 and 47,520, respectively. The model was divided into 72 elements circumferentially. Solid elements of 8 nodes were used for modeling. The axial cross section and mesh division of the model are shown in Fig.5.

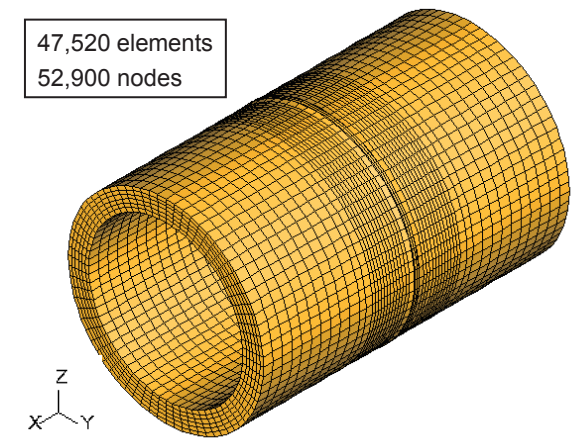

z

Fig. 4 Finite element analysis model

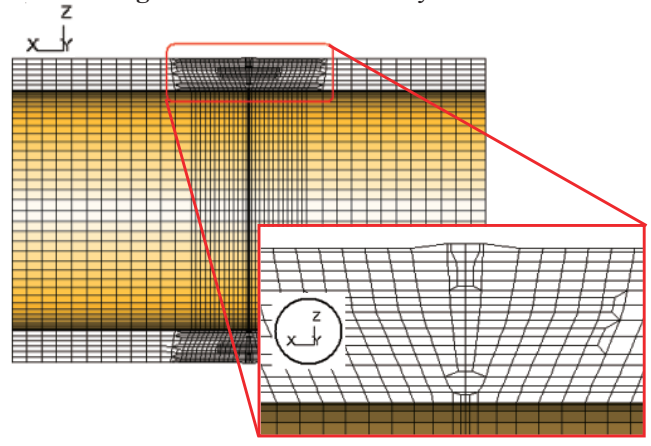

Fig. 5 Cross section of analysis model and mesh division

\subsection{Analysis conditions}

In this study, an unsteady heat conduction analysis was conducted using a moving heat source model. The amount of heat input was assumed based on the actual welding conditions. The interpass temperature was set to $150^{\circ} \mathrm{C}$ the same value as in actual welding conditions. Deposition of weld metal on the joint was simulated using the birth-death element technique in which each element was activated according as the weld heat source moved. For a thermal elastic plastic stress analysis, the isotropic hardening rule was used and the annealing effect in which welding heat affected a lower layer was taken into account. To express this effect, the amount of cumulative plastic strain was assumed to be zero in the region with a temperature above $800^{\circ} \mathrm{C}$. Many researchers have studied on which hardening rule is best ${ }^{4)}$. The isotropic hardening rule was reported to overestimate weld residual stress ${ }^{4}$. On the other hands, the combination of the consideration of annealing effect with the isotropic hardening rule was proposed to improve the accuracy of weld residual analysis much more than the independent employment of the rule ${ }^{5)}$. The stress analysis was conducted based on the stress-strain 
relationship represented by the strain-hardening coefficient.

The material constants were determined based on the results of material tests of test pieces cut from the mock-up joint and literature data ${ }^{6)}$. Figure 6 shows the dependence of material properties on temperature. The strain-hardening coefficients were calculated from the relationship between true stress and true plastic strain. The heat transfer coefficient was assumed to be 20 $\times 10^{-6} \mathrm{~W} /\left(\mathrm{mm}^{2} \cdot{ }^{\circ} \mathrm{C}\right)$.

The calculation was done using parallel computation of 4 CPUs with Intel Xeon X5260 (3.33 GHz) and 64 GB memory. SuSE Linux 9.3 was used as the operation system.

\subsection{Calculation time}

The calculation time was $9.2 \mathrm{~h}$ in the heat conduction analysis and $61.1 \mathrm{~h}$ in the thermal plastic elastic analysis using parallel computation of 4 CPUs. These times indicated that the finite element analysis using ISM could solve the large-scale welding problem at extremely fast speeds.

\section{Measurement by inherent strain method}

\subsection{Inherent strain method using functional form ${ }^{7}$}

The weld residual stress distribution was measured by the inherent strain method ${ }^{3)}$. In this method, variation of elastic strain is measured when weld residual stress of the mock-up is released by cutting it into pieces, and then the weld residual stress distribution is estimated by an elastic calculation using the inherent strain distribution obtained from the variation of strain.

In the inherent strain method using the functional form $^{7)}$ employed in this study, the inherent strain distribution is expressed using the functional form to decrease the number of measurements. To express the inherent strain distribution, the following polynomial function and the function combining the linear function and trigonometric polynomial function were used $^{8)}$.

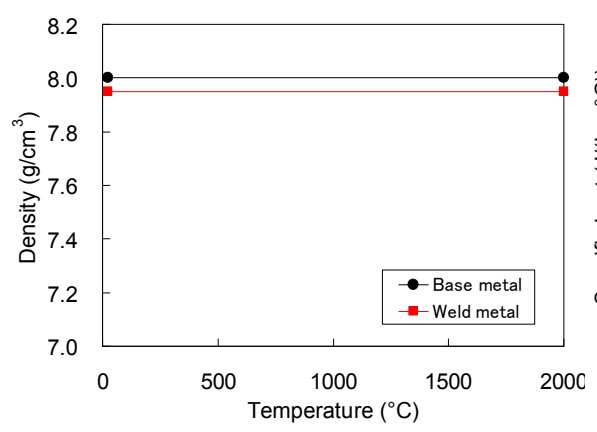

(a) Density

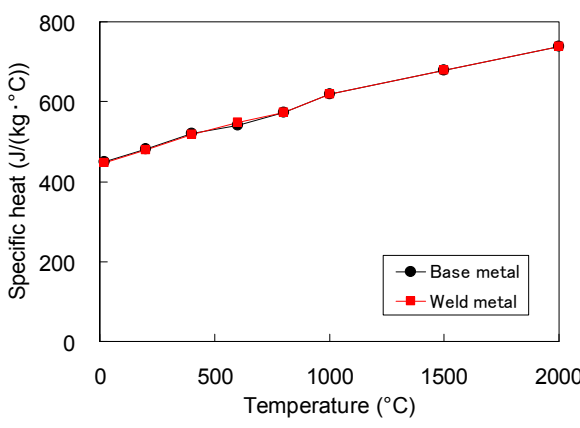

(b) Specific heat

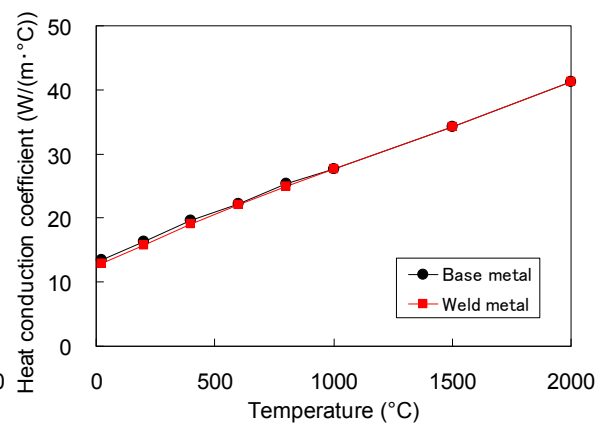

(c) Heat conduction coefficient

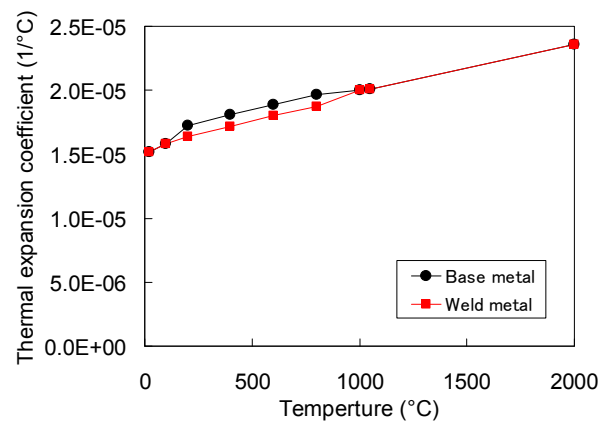

(d) Thermal expansion coefficient

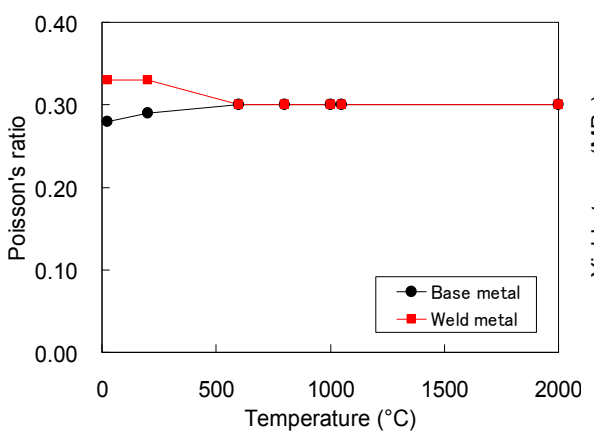

(f) Poisson's ratio

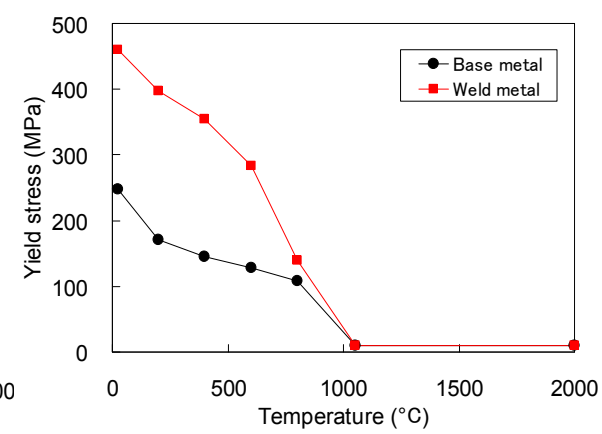

(g) Yield stress

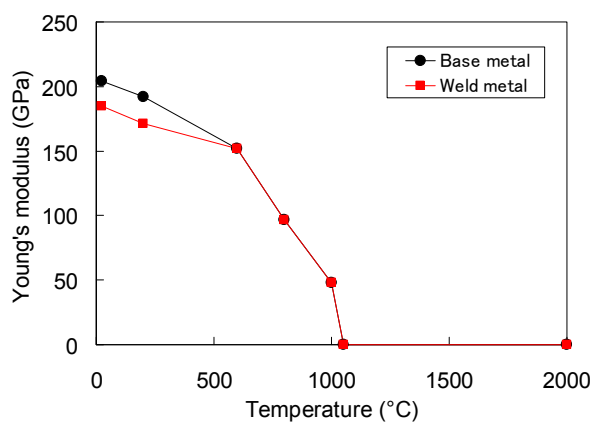

(e) Young's modulus

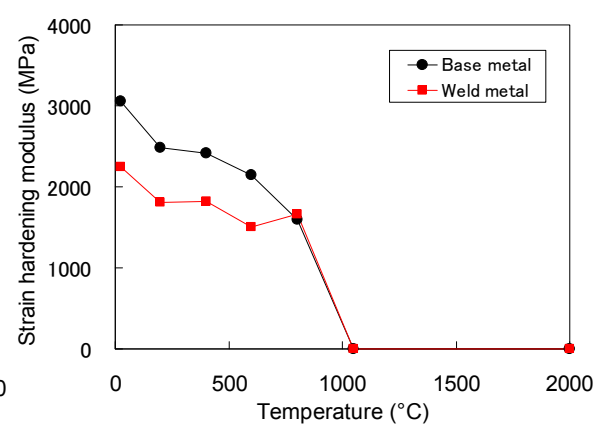

(h) Strain hardening modulus

Fig. 6 Dependence of material constants on temperature 


$$
\begin{aligned}
& \varepsilon_{k}^{* f}(\zeta, \xi)=\sum_{i=1}^{N} \sum_{j=1}^{N} A_{i j k}\left(1-\frac{\zeta}{Z_{k}}\right)^{i}\left(1-\frac{\xi}{R_{k}}\right)^{j} \\
& \varepsilon_{k}^{* f}(\zeta, \xi)=A_{1 k}\left(1-\frac{\zeta}{Z_{k}}\right)\left(1-\frac{\xi}{R_{k}}\right) \\
& +\sum_{i=1}^{N} \sum_{j=1}^{N} A_{i j k} \cos \left((2 i-1) \frac{\pi \zeta}{2 Z_{k}}\right) \cos \left((2 j-1) \frac{\pi \xi}{2 R_{k}}\right)
\end{aligned}
$$

Here, $\varepsilon_{k}^{* f}(\varsigma, \xi)$ denotes the distribution of inherent strain, $\zeta$ and $\xi$ show local coordinates in the axial and radius directions, $Z_{k}$ and $R_{k}$ are the axial and radial coordinates at the edges of regions including inherent strain in the local coordinate system, $A_{1 k}$ and $A_{i j k}$ are distribution coefficients of inherent strain, $N$ is the term number of the polynomial function, and $k=0,1,2,3,4$.

The 3D distribution of weld residual stress was estimated assuming an axisymmetric distribution and using Eq.(1), Eq.(2) and $N=3$. The estimation was calculated using an improved version on the basis of a program developed by Osaka University and Mitsubishi Heavy Industries, Ltd.

\subsection{Measured distribution of weld residual stress}

Figure 7 shows the through-thickness distributions of the weld residual stress of the mock-up measured by the inherent strain method using the functional form. They were chosen from the steady area, sufficiently far enough from the weld start and stop points. The three term function $(N=3)$ was chosen as the optimum function expressing inherent strain distribution considering the research results of Nakacho et al. ${ }^{9)}$ regarding a welded pipe joint. Detailed stress measurement results of the mock-up used in this study are summarized in ref. (10). Figure 7 includes the stress distributions at the weld center, and at locations in the base metal $20 \mathrm{~mm}$ and $40 \mathrm{~mm}$ from the weld center.

The measurement accuracy at each location was calculated by a statistical approach and the error bar was estimated on the basis of the standard deviation. The significant merit of the inherent strain method is its ability to estimate the measurement accuracy at positions from the inter-comparison of measured strain values. The maximum values of error bars obtained in this study were within $80 \mathrm{MPa}$ for hoop stress and within $50 \mathrm{MPa}$ for axial stress. Comparison of measurements accuracy between the three locations showed that the accuracy at the weld center was not better than for the others. This was thought to be why heterogeneity in the weld region caused local variation of the residual strain.

Comparison between two measurement values obtained by using Eqs.(1) and (2) at each position showed the distribution shapes were very similar but the compressive stresses in the inner side calculated by Eq.(2) tended to be larger than the stress values obtained by Eq.(1). The local stress values were assumed to vary around the two measurements because the weld residual stress distributions were represented as a smooth curve expressed by a function.

\section{Comparison of analysis and measurement results}

Figure 7 also compares the through-thickness distribution for the residual stress analysis results and measurements. The distributions were chosen from the steady area, excluding weld start and stop points. The distribution shapes of weld residual stress obtained by the analysis were similar to the measurement results. For the hoop stress at the weld center, the magnitude and occurrence position of the tensile stresses in the outer side agreed well between the analysis and the measurement though the compressive stresses for the inner side differed somewhat. For the hoop stress in the other two locations, the analysis and measurement values were in good agreement in most positions. For the axial stress, the magnitude and occurrence position of both compressive and tensile stresses all agreed very well. These results demonstrated that the weld residual stress analysis technique based on the ISM generally had sufficient computation accuracy, though the rough mesh division of the model used in this study was assumed to affect the stress analysis results somewhat.

\section{Conclusions}

The fast computation performance of the welding simulation method based on the ISM was examined and the analysis accuracy was validated by the stress distribution measured using the inherent strain method. It was clear that the simulation method could accurately solve large-scale welding problems within practical calculation times.

\section{Acknowledgements}

The authors thank Mr. A. Kawahara, Mr. M. Morishita and Prof. N.X. Ma of Osaka University for their cooperation.

\section{References}

1) H. Murakawa, I. Oda, S. Ito, H. Serizawa, M. Shibahara and H. Nishikawa: Iterative substructure method for fast computation of thermal elastic plastic welding problems, J. Kansai Soc. Nav. Archit., Jpn., 243 (2005), 67-70.

2) A. Maekawa, S. Takahashi, H. Serizawa and H. Murakawa: Fast computational residual stress analysis for welded pipe joint based on iterative substructure method, ASME 2011 Pressure Vessels and Piping Division Conference, PVP2011-57237, Baltimore (2011). 
3) Y. Ueda, K. Fukuda, K. Nakacho and S. Endo: A new measuring method of residual stresses with the aid of finite element method and reliability of estimated values, J. Soc. Nav. Archit. Jpn., 138 (1975), 499-507.

4) P. Gilles, W. El-Ahmar and J-F. Jullien: Robustness analyses of numerical simulation of fusion welding NeT-TG1 application: "Single weld-bead-on-plate", Int. J. Pres. Ves. Pip.86 (2009), 3-12.

5) A. Maekawa, A. Kawahara, H. Serizawa and H. Murakawa: Residual stress study in dissimilar metal welds of a PWR pressurizer surge nozzle: validation of developed fast analysis method and examination of safe-end length effect, ASME 2013 Pressure Vessels and Piping Division Conference, PVP2013-97176, Paris (2013).

6) M. Mochizuki, K. Enomoto, N. Okamoto, H. Saito and E. Hayashi: Study on production mechanism of welding residual stress at the juncture of a pipe penetrating a thick plate, Quarterly Journal of JWS, 12-4 (1994), 561-567.

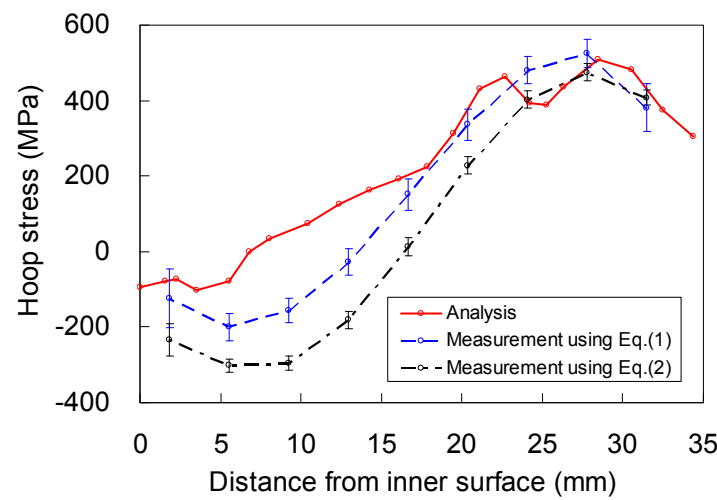

(a) Hoop stress at weld center

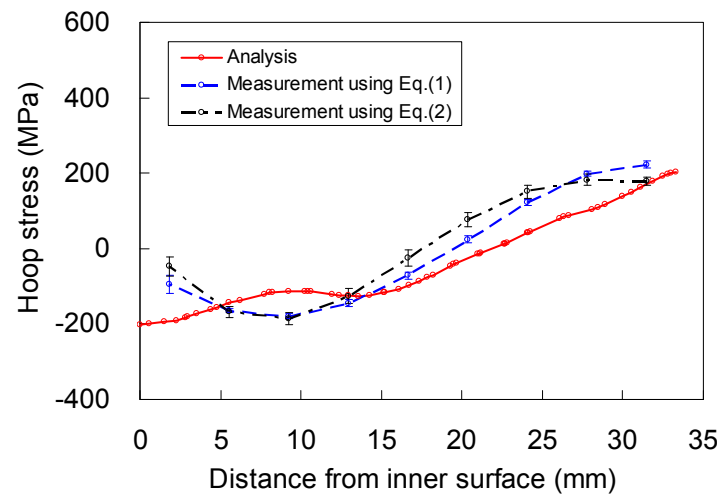

(c) Hoop stress at $20 \mathrm{~mm}$ location from weld center

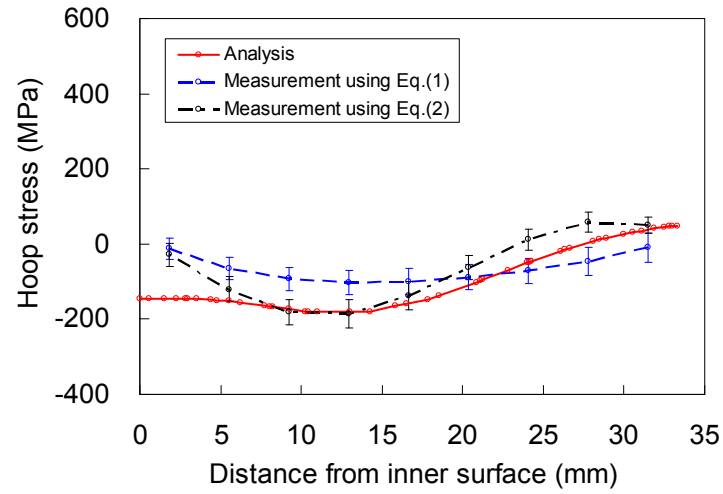

(e) Hoop stress at $40 \mathrm{~mm}$ location from weld center
7) Y. Ueda and N.X. Ma: Expression of inherent strain in form of function and its estimation, Quarterly Journal of JWS, 11-1 (1993), 189-193.

8) K. Nakacho, T. Ohta, N. Ogawa, N. Ma, H. Hamaguchi, M. Satou and M. Nayama: Measurement of welding residual stresses of reactor vessel by inherent strain method -Measurement of residual stresses of pipe-plate penetration joint-, Quarterly Journal of JWS 25-4 (2007), 581-589.

9) K. Nakacho, A. Maekawa, R. Sato, N. Kasahara and K. Aoki: Three-dimensional measurement of welding residual stress of thick coolant pipe joint in nuclear reactor plant by inherent strain method, Quarterly Journal of JWS, 29-4 (2011), 335-345.

10) A. Maekawa, K. Nakacho, N.X. Ma and R. Sato: Residual stress measurement large-bore stainless steel pipes with butt-welded joints by inherent strain method, Trans. JWRI, 39-2 (2010), 65-67.

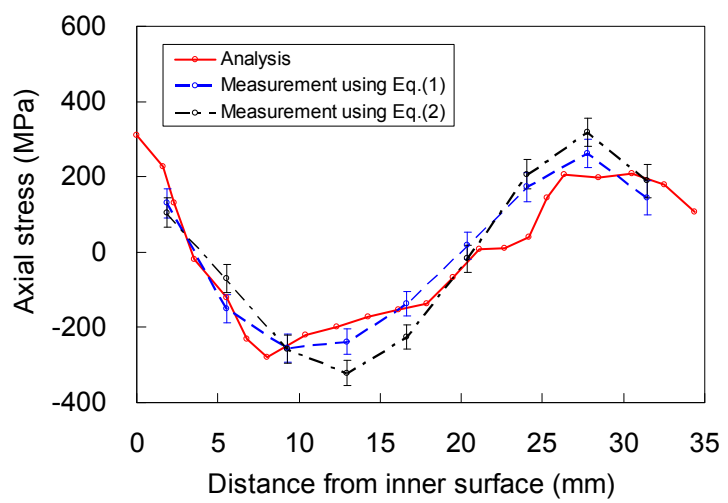

(b) Axial stress at weld center

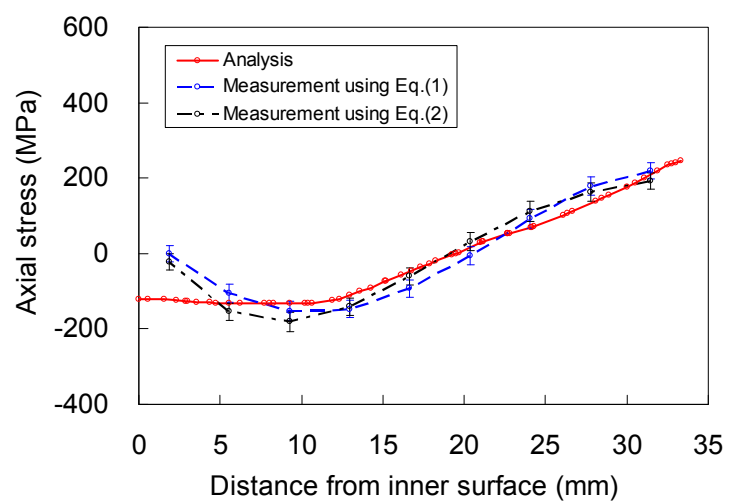

(d) Axial stress at $20 \mathrm{~mm}$ location from weld center

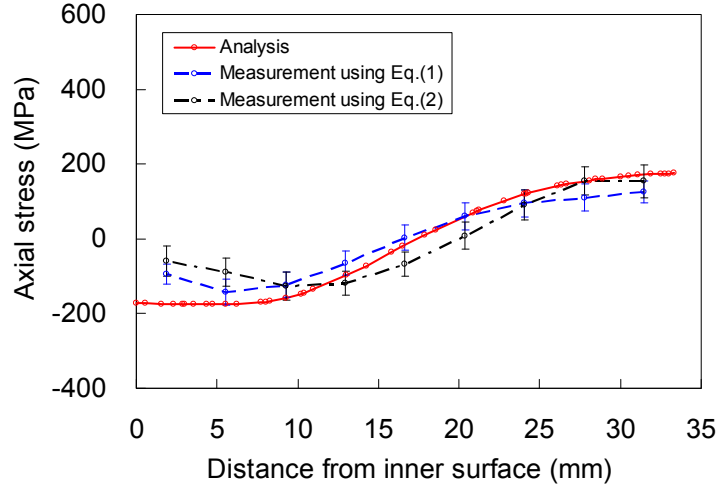

(f) Axial stress at $40 \mathrm{~mm}$ location from weld center

Fig. 7 Comparison of through-thickness distribution of weld residual stress between analysis and measurement 